\title{
Peer Feedback Improves Students' Academic Self-Concept in Higher Education
}

\author{
Bianca A. Simonsmeier ${ }^{1} \cdot$ Henrike Peiffer $^{2} \cdot$ Maja Flaig $^{1} \cdot$ Michael Schneider $^{1}$
}

Received: 12 November 2018 / Published online: 23 March 2020

(c) The Author(s) 2020

\begin{abstract}
Peer feedback has been shown to be an effective strategy to improve academic achievement. However, little evidence is available about the effects of peer feedback on academic outcomes other than achievement, such as academic self-concept (ASC). ASC and achievement are reciprocally related and thus mutual reinforce themselves. The present study focuses on the effect of a four week long structured web-based peer feedback intervention on ASC in the domain of academic writing as a part of a seminar assignment in a sample of undergraduate psychology students. The study investigated the effectiveness with 49 students in a randomized-controlled trial with a pre-and post-test. Each student acted as an author and a reviewer. Results indicated significant improvements in ASC for the domain of academic writing over time as compared to a control group. Furthermore, the causal effect of peer feedback compared to no feedback on ASC for academic writing was strong with $d=0.72$. The effect was domain specific, as the ASCs for the sub-domains statistics and language remained unchanged by the intervention. Overall, the results revealed that participation in a peer feedback system is an effective method to enhance ASC in the context of higher education.
\end{abstract}

Keywords Peer feedback - Academic writing - Academic self-concept - Higher education

\section{Introduction}

The higher education funding council for England states that effective feedback helps learners to "progress with confidence and skill as lifelong learners" (HEFCE 2010, p. 8). One type of feedback is peer feedback that has become an increasingly central aspect for learning and teaching strategies in higher education (Brown 2010; Maringe 2010). Peer feedback engages students in their own learning process while taking both the roles of an examiner and examinee. Thus, this teaching method initiates an active and self-directed learning process, which includes social interaction and reciprocal teaching. There exists a large body of literature about various aspects and effective practices implementing peer

Bianca A. Simonsmeier

simonsm@uni-trier.de

1 Educational Psychology, Fachbereich I, Universität Trier, 54286 Trier, Germany

2 I/O Psychology, Fachbereich I, Universität Trier, 54286 Trier, Germany 
feedback in traditional classroom instruction (e.g., Falchikov 2001; Falchikov and Goldfinsh 2000; Gielen et al. 2011; Topping 2005). New technologies being available initiated a trend towards the employment of a blended-learning approach and online learning environments such as Massive Open Online Courses (MOOCs, Suen 2014). Resulting, peer feedback gets further relevant, as interactivity of learners including feedback is a key component of online learning (Costello and Crane 2013; Piech et al. 2013). For example, methods for feedback in MOOCS are collaborative discussion forums or peer grading as a form of peer feedback besides other peer learning opportunities (e.g., Costello and Crane 2013).

However, previous research in higher education almost exclusively focused on the effects of peer feedback on learning processes and academic achievement (Topping 1998; Topping et al. 2000; Venables and Summit 2003). Much less is known about the effects of peer feedback on academic outcomes other than academic performance. The role of intrapersonal and interpersonal competencies is currently highlighted by higher education researchers and policy makers in order to support student success (National Academies of Sciences 2017). Universities should therefore go beyond teaching only intellectual skills, but also foster achievement-related competencies (Marsh and Hau 2003) and the related individual perceptions such as academic self-concept (ASC), i.e., the mental representation of one's own abilities in academic domains (Brunner et al. 2010). There is strong evidence that ASC affects students' learning, effort, and persistence when faced with failure; moreover, ASC is reciprocally related to academic achievement (Robbins et al. 2004; Valentine et al. 2004). As peer feedback enhances students' academic achievement in higher education, it might simultaneously improve the achievement-related construct of ASC (e.g., Chen et al. 2013). There has been much empirical support for the reciprocal relation of ASC and achievement in different educational contexts, thus, high achievement is associated with high ASC and vice versa (e.g., Chen et al. 2013; Pinxten et al. 2014). To our knowledge, the present study is the first to investigate the effects of peer feedback on ASC instead of achievement in higher education.

\section{Peer Feedback in Higher Education}

Peer feedback is defined as "a communication process through which learners enter into dialogues related to performance and standards" (Liu and Carless 2006, p. 2). It represents a teaching method that engages students in their own learning process while taking both the roles of an examiner and examinee. Related, but conceptually different is peer assessment, which describes students grading the work or performance of their peers using relevant criteria (Falchikov 2001). Peer feedback therefore differs from peer-assessment in that no formal grades are awarded and that the focus lies on understanding and enhancing learning rather than providing a summative assessment of performance. One of the main aims of feedback is to bridge the gap between the students' actual performance level and the desired level of performance (Lizzio and Wilson 2008).

In the context of higher education, peer feedback has been shown to enhance self-regulatory practice, metacognition, students' learning, and academic achievement (Black and William 1998; Cartney 2010; Falchikov 2001; Hattie and Timperley 2007; Nicol 2010; Rust 2002; Sluijsmans et al. 2002). Providing peers with feedback is associated with performance improvements and an increase in motivation (Bargh and Schul 1980). Receiving feedback from peers helps students to identify and understand their errors prior to assessment (Taras 2002), to develop objectivity in relation to standards (Nicol and MacFarlaneDick 2005), and to monitor their own work process and progress (Butler and Winne 1995). 
While giving and receiving feedback are both effective, giving feedback has an even greater impact on performance than receiving feedback (Kim 2009).

The quality and the effectiveness of peer feedback depend on characteristics of the feedback and the feedback practice employed. One of the most intensively researched feedback characteristic is feedback valence, specifying whether the feedback is positive or negative (Lechermeier and Fassnacht 2018). While positive feedback has the ability to enhance both performance and perceptions of one's own competencies; research has shown mixed results for the effect of negative feedback (e.g., Kluger and DeNisi 1996; Lechermeier and Fassnacht 2018; Van Dijk and Kluger 2011). On a theoretical level, it is argued that negative feedback may enhance efforts to improve performance (Bloom and Hautaluoma 1987; Fedor et al. 2001). On the other side, negative feedback may be perceived as threat to the self-concept, so that cognitive resources are shifted from the task and redirected to the self (Baadte and Schnotz 2014). Following, less cognitive resources are available for the actual task, which may ultimately lead to decreases in performance (Kluger and DeNisi 1996; Vancouver and Tischner 2004). Determining and following feedback principles can help students so see feedback as a valuable tool without threatening the self. Key principles of effective feedback practices are guidance on assessment and requirements of assessment, training in giving peer feedback, and clarification of the role the student takes in the feedback process (Evans 2013). The quality of peer feedback can be enhanced by blinding the process (Cho and Cho 2011), not asking students to provide grades (Nilson 2003), and using a structured evaluation form (Marcoulides and Simkin 1995).

In summary, there is cumulative evidence that peer feedback is positively associated with academic achievement in higher education (e.g., Cartney 2010; Falchikov 2001; Nicol 2010; Rust 2002; Sluijsmans et al. 2002) when key principles for effective feedback are followed (Baker 2016; Topping 1998). Most evaluations of the effectiveness of peer feedback focused on academic achievement as the only outcome measure. Much less is known about the effects of peer feedback on ASC as one central achievement-related outcome in higher education (Robbins et al. 2004) and K-12 education (Valentine et al. 2004). In order to fill this research gap, we aim to investigate the effects of peer feedback on ASC in higher education. To understand the effect of peer feedback on ASC more clearly, we further consider the valence of the feedback received from the peers as a potential moderator.

\section{Conceptualization of ASC}

ASC is defined as the mental representations of one's own abilities (Brunner et al. 2010) and refers to how individuals view themselves in specific academic domains (e.g., Byrne 1984). Research provides many examples for the positive effects of a student's high ASC, highlighting the relevance of intrapersonal competencies and related individual perceptions. For example, ASC is associated with high achievement, persistence when faced with failure, interest, and academic choice (Gogol et al. 2017; Köller et al. 2006; Marsh et al. 2005; Núnez et al. 2005). Students with positive ASC reach higher educational attainment levels and have more success in career entrance (Guay et al. 2004; Pinquart et al. 2003). In the context of higher education, ASC is described as one of the key variables of university students' successful education (Richardson et al. 2012; Robbins et al. 2004; Schneider and Preckel 2017). Besides the association with performance outcomes, positive ASC is associated with more distal indicators of academic achievement, for example less university 
dropout (Schiefele et al. 2007). Thus, there is growing recognition that a student's positive ASC can facilitate a whole range of educational outcomes (Trautwein and Möller 2016).

Teachers and peers can systematically affect ASC in academic contexts. Prior research has identified four main influences on ASC, namely (1) frame of reference, (2) causal attributions (3) reflected appraisals from significant others, and (4) mastery experiences (Bong and Skaalvik 2003). Firstly, the most relevant influences on forming ASC are processes of comparisons (Jansen et al. 2015), so that students compare self-beliefs of their own skills with the perceived skills of other students within their frame of reference (e.g. classmates; Marsh et al. 1991). Dimensional comparisons within an internal frame of reference and social comparisons within an external frame of reference are described in the internal/ external frame of reference (I/E) model (e.g., Marsh 1986) that originally relates math and verbal achievement to corresponding measures of ASC (Möller and Marsh 2013). Dimensional comparison describes the formation of ASC in relation of an internal reference. For example, students compare their own skills across different academic domains (e.g., different subjects; Möller and Marsh 2013; Möller et al. 2009). External comparison refers to situations in which students compare their own skills in a particular school subject with the perceived skills of other students in the same school subject within their frame of reference (e.g., classmates, Marsh et al, 2015). The source of comparison leads to multidimensionality of ASC, so that students' ASC is hierarchically structured with domain-specific facets according to different subjects of ASC at the bottom and a general ASC at the apex. The assumption of multidimensional facets has been replicated for different age groups (e.g., Byrne and Gavin 1996), gender (Jansen et al. 2015), and cultures (Arens et al. 2014).

Secondly, the causes to which students attribute previous success and failure influence subsequent self-concept and the self-concept in turn form later attributions (Bong and Skaalvik 2003). Self-concept and attributions are related reciprocally. The types of causal attributions relating to previous successes and failures influence subsequent self-concept; in turn, the self-concept affects later attributions (e.g., Skaalvik 1997). Thirdly, receiving reflected appraisals from others (e.g., peers, parents, or teacher) shape students' ASC, as they adopt their reflections of other people 's appraisals (Bong and Skaalvik 2003). For example, Rosenberg (1979) claimed that "...there is probably no more critical and significant source of information about ourselves than other people's views of us."

Fourthly, mastery experiences in academic domains influence students' beliefs of their own abilities in these domains, e.g. achievement in academic writing forms ASC in academic writing. The reciprocal effects model (Marsh 1990) provides information about reciprocal relations between ASC and academic achievement over time. The combination of REM studies in a meta-analysis including data from over 50,000 students demonstrated that ASC relates to subsequent achievement, even after controlling for the effects of prior achievement (Valentine et al. 2004). In higher education, for, example, prior achievement in academic writing forms ASC in academic writing (e.g., Bandura 1986).

\section{Effects of Peer Feedback on ASC}

As ASC is malleable (e.g., Craven et al. 1991; O'Mara et al. 2006; van Dinther et al. 2011), peer feedback may contribute to changes in writing performance (Nelson and Schunn 2009). And as ASC and achievement are positively correlated (e.g., Marsh and Martin 2011), we believe that peer feedback has the potential to improve students' ASC in writing. Peer feedback induces comparison processes so that students evaluate their achievement in one domain (e.g., academic writing) in relation to the achievements 
of their fellow students. Likewise, students who receive positive feedback from peers improve their ASC and subsequent achievement (Bouchey and Harter 2005). However, interventions fostering ASC have been primarily constructed to investigate the effects of different types of performance feedback (e.g., performance feedback by teachers; Craven et al. 1991) (for an overview see O'Mara et al. 2006). We are not aware of quantitative evidence of the effects of peer feedback on ASC in different educational settings in general, and in particular in the context of higher education.

\section{The Present Study}

Peer feedback has been proven to be an effective method to foster learning processes and to enhance academic achievement (Topping 1998; Topping et al. 2000; Tseng and Tsai 2007; Venables and Summit 2003). By contrast, almost nothing is known about whether peer feedback increases achievement-related outcomes, such as ASC, although there are good reasons to believe that this might be the case (Nelson and Schunn 2009). For example, a reciprocal relationship between ASC and academic achievement has been observed (Chen et al. 2013; Valentine et al. 2004). Therefore, in the present study, we investigated the effects of peer feedback on ASC in a higher education sample. The study aimed to answer three central questions:

1. Does peer feedback enhance ASC in the domain of academic writing in higher education? Based on previous findings (e.g., Chodkiewicz and Boyle 2014; Dempsey et al. 2009), we hypothesized that peer feedback enhances university students' ASC in the domain of academic writing and that the effect is causal.

2. Is the effect of peer feedback on ASC domain specific? We hypothesized that peer feedback on a seminar paper has a significant impact on changes in ASC relating to academic writing but not on ASC related to language competence or statistics, because ASC has a multifaceted hierarchical structure (Marsh and Shavelson 2010) and peer feedback on academic writing targets only one of these facets.

3. Is there an interaction effect of pretest ASC and valence of the received feedback on posttest ASC? We adopt an individual difference perspective on feedback (Baadte and Schnotz 2014) and expected to find a moderating effect, so that peer feedback has weak effects on (posttest) ASC when the feedback valence matches students' (pretest) ASC (e.g., valence is positive, pretest score is high) and thus, does not interfere with their ASC. We expected that peer feedback has a strong effect on (posttest) ASC when the feedback valence differs from students' (pretest) ASC and thus, presents them with new information.

To investigate these three research questions, we conducted an online intervention study embedded in students' regular classes in a Bachelor of Science Psychology program. Academic writing is a central competence in Psychology and related social sciences (Topping et al. 2000). We examined the causal effect of peer feedback on ASC in a randomized controlled field experiment with a pretest-posttest design, in which half of the students participated in the peer feedback intervention, and the other half formed a waiting control group. 


\section{Method}

\section{Participants}

Participants were recruited from three undergraduate courses in educational psychology, which were part of the Bachelor of Science Psychology program at a public rural university in Germany. Student admission is based on their high school GPA for this program. There were no students from abroad in any of the classes. Each course comprised 30-33 participants in total. The participants were required to hand in a seminar paper at the end of the semester in order to pass the course. The participation in the study was voluntary. Data was collected from 52 students who decided to participate in the study. The students were randomly assigned to an intervention group or a control group on an individual level across all three courses. The intervention group used the online peer review system whereas the control group just handed in their papers without providing or receiving any peer feedback.

The final sample resulted in 49 students $(75.5 \%$ female), as three students did not hand in their paper in time and were therefore excluded from the study. The participants' age ranged from 21 to 29 years with a mean of 23.51 years $(S D=2.01)$. They were in the second $(2 \%)$, third $(8 \%)$, fourth $(31 \%)$, fifth $(57 \%)$, or ninth $(2 \%)$ semester of their bachelor program. The number of students' experiences in academic writing varied considerably in the sample. Of all students, $12.2 \%$ never had written a scientific paper before. The remaining $87.8 \%$ students had written between 1 and 14 scientific papers with a mean of 2.23 papers $(S D=2.06)$.

\section{Writing Task}

The exact task was to write a scientific paper on an individually selected topic. The students had to design a study and include results of real or anticipated data relating to their research question. The required length of the assigned papers was five pages. The papers all had the same structure and included an introduction, theory, methods, results, and discussion section, followed by the bibliography. Students also included figures and tables supporting the results section.

\section{Procedure and Peer Feedback}

The study was conducted in full accordance with the Declaration of Helsinki and the APA Ethics Code (American Psychological Association 2002). Prior to their participation, students were informed about the following four points. First, about the purpose of the study, the procedures, and study duration. Second, that participation is voluntarily and that it may be terminated at any point. Third, that there are no potential risks, discomfort or adverse effects with regard to their participation. Fourth, that data is collected anonymously, and that even though some personal data (e.g., e-mail addresses) will be collected for organizational purposes, these data will not be used to identify individual participants and will be destroyed as soon as possible. We hold all participants' written consent on file.

We employed a randomized controlled trial field experiment including a peer feedback intervention in regular one-semester undergraduate courses in Psychology. We chose this approach to examine the effectiveness of peer feedback on ASC in a realistic setting providing high external reliability. All courses used a web-based feedback system (PEer REview ONline; PEREON) developed for this study. The feedback process was double-blinded, 
that is, the students did not know whose paper they reviewed or who reviewed their paper. Providing and receiving feedback worked in three phases. In the first phase, all students handed in their paper prior to a due date. Following, the system randomly assigned students of the same course as reviewers for the papers. In the second phase, the students reviewed the assigned paper and evaluated the paper based on multiple-choice items in the webbased feedback system. Students provided feedback on eight dimensions on scales from zero (strongly disagree) to five (strongly agree). Dimensions one to seven corresponded with the typical sections of a scientific paper and the eight dimension related to language and formatting of the paper. The dimensions were: (1) abstract (four items; e.g., "The abstract contains a summary of the study including the gap in research an hypotheses"), (2) introduction (four items; e.g., "The paper contains an interesting first paragraph"), (3) theoretical background (eight items; e.g., "The paper includes adequate psychological theories, concepts, and empirical findings, which are related to the hypotheses"), (4) methods (five items; e.g., "The design is clearly presented."), (5) results (three items; e.g., "The results are clearly presented in relation to the hypotheses."), (6) discussion (five items; e.g., "The conclusion drawn from the results are reasonable and discussed in relation to relevant theories and empirical findings), (7) references (three items; e.g., "The references are cited in accordance to the APA publication manual."), and (8) language and formatting (three items, e.g.; Central concepts and technical terms are defined and used consistently."). Students also had the opportunity to give open peer feedback by writing a text at the end of the form. In the third phase, the students accessed the peer feedback for their own paper. Each phase had a duration of one week. Assessments took place between the three weeks before the students had to hand in their papers (T1) and in the next session of the course after receiving the feedback (T2). The procedure is visualized in Fig. 1. To make sure all students received the same intervention, we implemented several checks in the online system. For example, students had to answer all questions in order to be able to save their provided peer feedback. We examined the open question to make sure students engaged in the task as expected. Further, we checked that the students logged in again to view there feedback once we enabled this function.

We tried to foster high quality feedback by following established practices for implementing valid peer feedback summarized in the introduction and recommended by Baker (2016). That is, we double-blinded the peer review process, did not provide grades for the

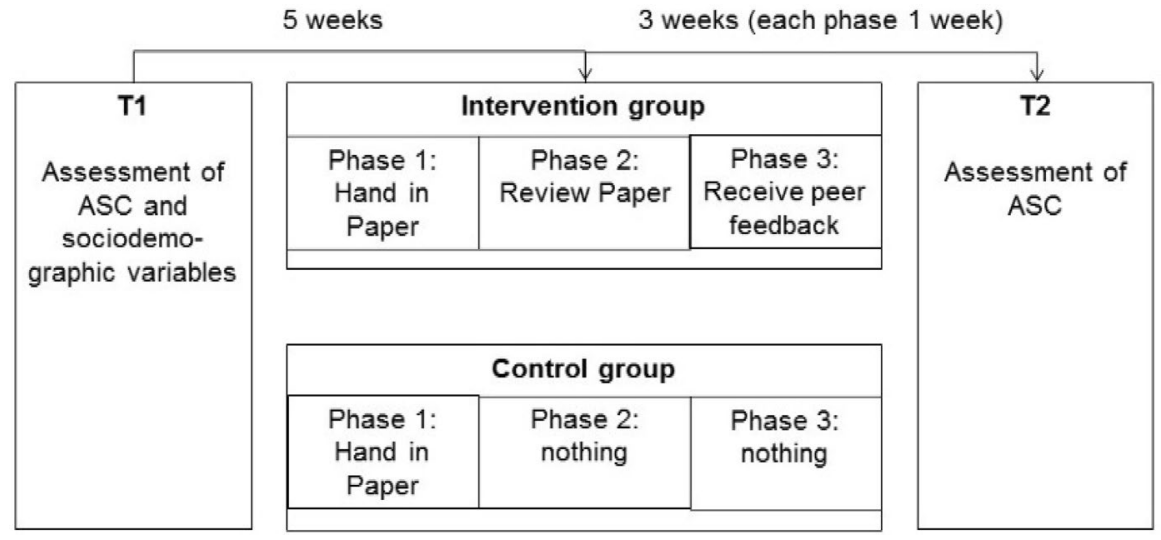

Fig. 1 Overview of the timing of assessment points and intervention and control period, respectively 
paper, and used a structured evaluation form. We further tried to enhance motivation to actively engage in the peer feedback process by incorporating a summative component in form of Likert-scale ratings and feedback in an open format (Pond et al. 1995).

\section{Measures}

The reliabilities of all measures at the two measurement points are provided in Table 1 . We assessed the cognitive component of three dimensions of ASC: self-concept relating to academic writing (three items), language (three items), and statistics (three items). We included the scales language and statistics as control variables. Items were an adapted version of the Self Description Questionnaire III (SDQ III; Marsh and O'Neill 1984). The response format was a Likert-scale ranging from one (does not apply at all) to six (does fully apply). Internal consistencies were acceptable and ranged from $\alpha=0.703$ to $\alpha=0.900$ for the different subscales and the two measurement points.

Feedback valence was derived from the feedback students received from their peers. We used the feedback on 35 items of eight dimensions as described in the section "Procedure and Peer Feedback" above. The higher the value, the more positive the feedback valence. Internal consistency was reliable with $\alpha=0.732$. We additionally asked the students to report their gender, age, semester, and their writing experience, that is, how many scientific papers they had already written in school.

\section{Statistical Analyses}

For all analyses, we set the $\alpha$-level to 0.05 . First, we calculated Pearson correlations for all dependent and control variables within and across the two measurement points. Second, we performed a MANOVA to calculate the effects of peer feedback on the outcome variables. Because gain scores are more meaningful than raw posttest scores, we performed the analyses for absolute gain scores whenever possible. Third, we performed moderation analyses using PROCESS in SPSS. We performed the analyses using the template of Model 1 (moderation model) in PROCESS (Hayes 2013).

\section{Results}

\section{Interrelations of dependent and control variables}

We calculated the correlations between the three ASC measures, semester, and scientific writing experience (see Table 2). Neither the students' semester nor the students' prior

Table 1 Internal consistencies (Cronbach's $\alpha$ ) of the dependent variables at $\mathrm{T} 1$ and $\mathrm{T} 2$

\begin{tabular}{lll}
\hline Measure & T1 & T2 \\
\hline ASC academic writing & .792 & .882 \\
ASC linguistics & .895 & .919 \\
ASC statistics & .816 & .869 \\
Feedback valence $^{\mathrm{a}}$ & - & .732 \\
\hline
\end{tabular}

${ }^{\text {a }}$ The variable was peer assessed 


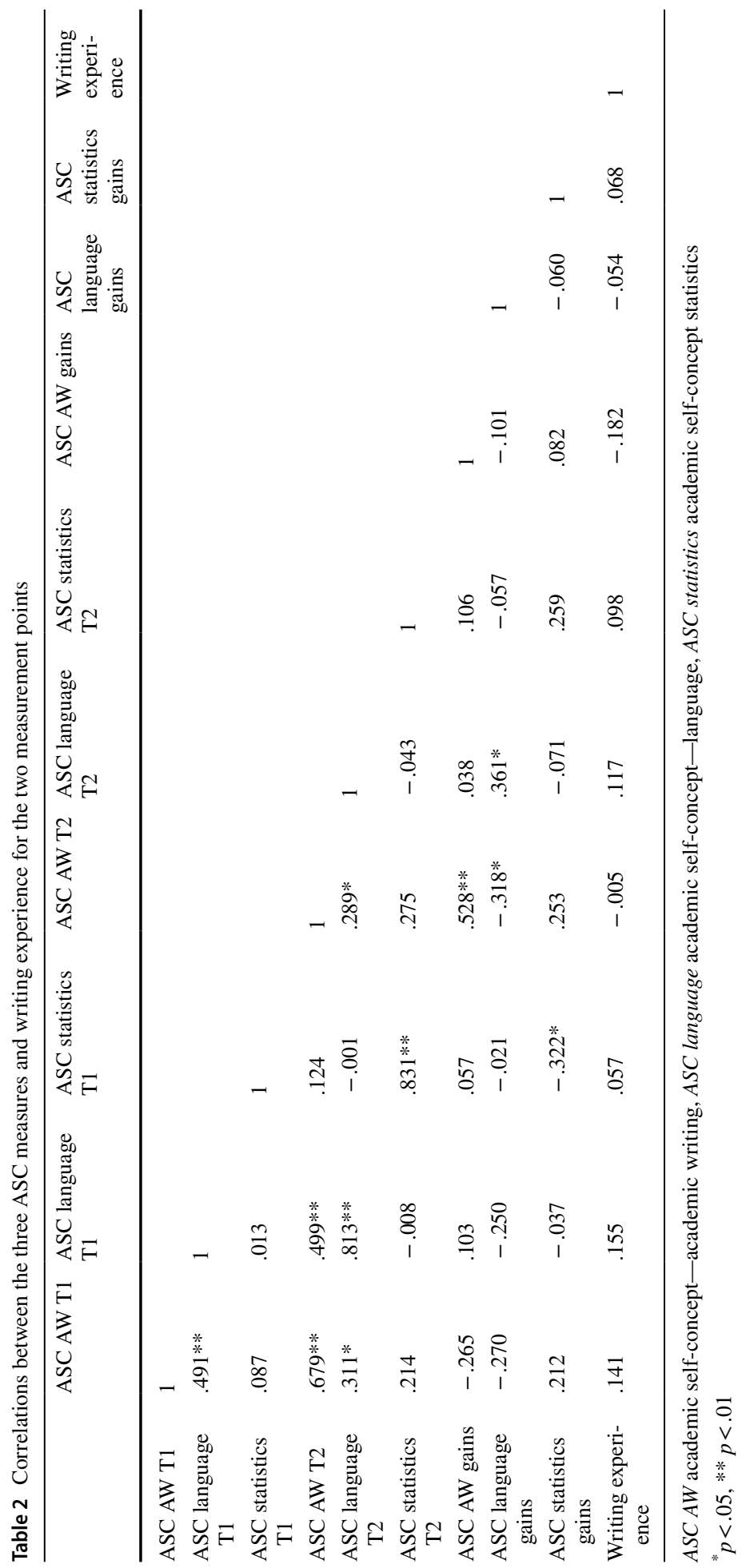


writing experience was significantly associated with any of the ASC variables. It is therefore unlikely that the effects of the intervention are moderated by these control variables.

\section{Effect of peer feedback on ASC}

The means, standard deviations, and change over time of the measures are displayed in Table 3. Due to the randomization, at T1, the intervention and control group did not differ in any of the ASC measures, gender, age, semester, and prior writing experience (all $p s>0.101)$.

We found evidence for our first hypothesis, that students in the intervention group had larger gains in ASC compared to students in the control group (see Table 4). The increase in ASC relating to academic writing was significant with $F(1)=5.90, p=0.019, d=0.721$. Controlling for semester and writing experience did not change this pattern of results. Because we used an experimental design, the group difference is evidence for a causal effect of web-based peer feedback on ASC.

We further found evidence for the second hypothesis, that is, that the effect of the feedback intervention on ASC is domain specific. There was no significant gain from pretest to posttest for language ASC and statistics ASC (see Table 4), which had not been targeted by our intervention. Controlling for semester and writing experience did not alter this pattern of results.

We found partial support for our third hypothesis. We did not find an interaction effect of pretest ASC and feedback valence on posttest ASC for ASC academic writing and ASC language (all $p s>0.198$, see Table 5 for more details). We did find a moderating effect of feedback valence on the relationship between pre- and posttest ASC statistics with $F(1,20)=6.30, p=0.021$, change in $R^{2}=0.062$. Peer feedback had weak effects on (posttest) ASC statistics when the feedback valence had the same direction as students' pretest ASC in statistics (e.g., positive valance, high pretest scores) and peer feedback had strong effects on ASC statistics when the direction of feedback valence differed from students' pretest ASC in statistics (e.g., positive valance, low pretest scores). As a result, students with low ASC at T1 receiving positive feedback (high valence) benefited most from the peer feedback intervention by increasing their ASC. Figure 2 visualizes this moderating effect.

\section{Discussion}

\section{Peer Feedback as a Tool to Enhance ASC}

The aim of the present study was to evaluate whether peer feedback on a seminar paper enhances ASC in the domain of academic writing in university students and whether this effect is causal and domain-specific. The findings support our first hypothesis, that peer feedback increases ASC in academic writing. The increase was significantly higher when participants received peer feedback compared to when they received no peer feedback. The magnitude of the effect of peer feedback on ASC is comparable to the effect of feedback on academic achievement in previous studies. We found an effect size $d=0.721$ for improvements in ASC. A comprehensive synthesis of more than 1200 meta-analyses investigating variables related to student achievement found a very similar effect size $(d=0.73)$ for the association of feedback with achievement (Hattie 2015). Whereas this effect size 


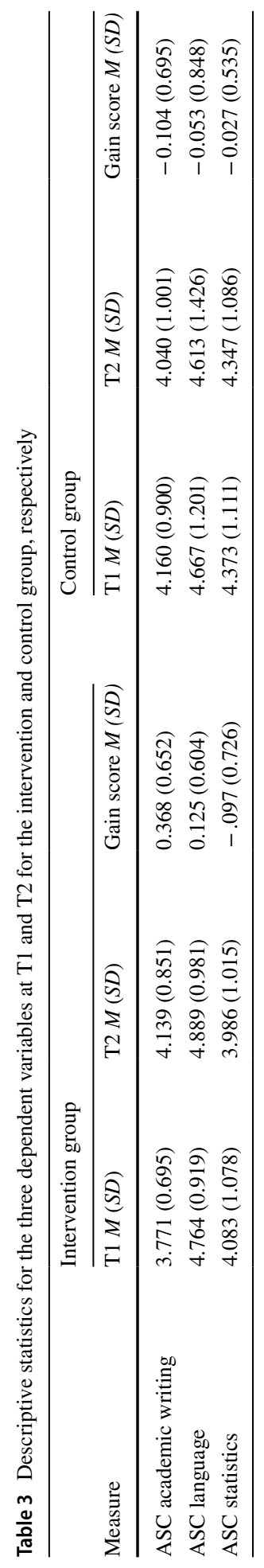


Table 4 Results from the MANOVA comparing gain scores across the intervention group and control group for the three ASC measures

\begin{tabular}{lllll}
\hline Measure & $F$ & $d f$ & $p$ & $d$ \\
\hline ASC academic writing & 5.90 & 1 & .019 & 0.721 \\
ASC language & 0.82 & 1 & .370 & 0.241 \\
ASC statistics & 0.20 & 1 & .654 & 0.111 \\
\hline
\end{tabular}

Table 5 Change in $R^{2}$ with the corresponding $\mathrm{p}$-values for the interaction effect between ASC at $\mathrm{T} 1$ and feedback valence on ASC at T2

\begin{tabular}{llc}
\hline & $\begin{array}{l}\text { Interaction effect of feedback } \\
\text { valence and pretest ASC on post- } \\
\text { test ASC }\end{array}$ & $p$ \\
\cline { 2 - 3 } Change in $R^{2}$ & .902 \\
ASC academic writing & .004 & .193 \\
ASC linguistics & .030 & .021 \\
ASC statistics & .062 & \\
\hline
\end{tabular}

$N=24$

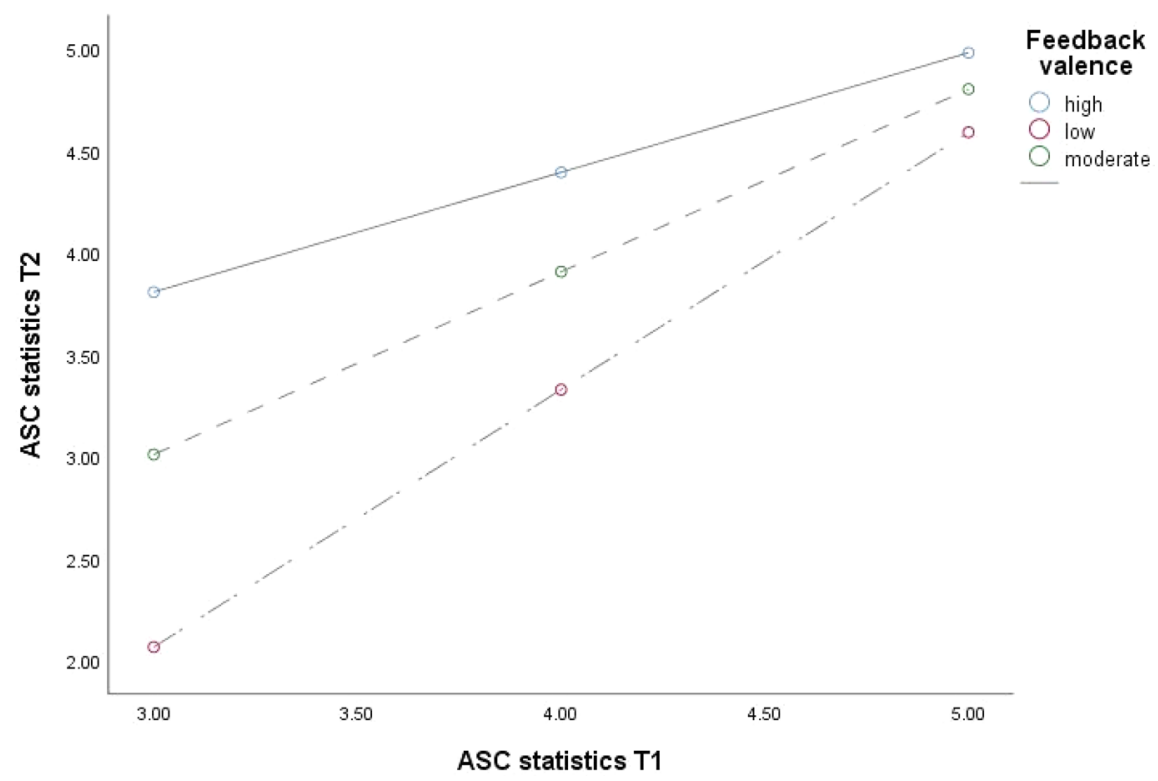

Fig. 2 Moderating effect of feedback valence on the relationship between pre- and posttest ASC statistics for the intervention group

pertains to feedback in general, and not to peer feedback specifically, it is still remarkable that the magnitudes are so similar. As we employed a randomized-controlled trial, the effect demonstrated in our study is causal rather than correlational, further supporting our first hypothesis. Peer feedback on academic writing exclusively affected academic writing ASC, but neither ASC for language and statistics. This result gives evidence for our 
second hypothesis that the effect of the intervention is domain-specific. According to a multidimensional perspective of ASC, interventions are more effective when constructed with regard to specific domains (O'Mara et al. 2006). Thus, interventions need to recognize the multidimensionality of ASC by targeting specific facets of self-concept (Craven et al. 1991).

The results partially supported our third hypothesis, that is, that the relationship between pretest and posttest ASC is moderated by peer feedback valence. We only found a moderating effect for ASC in statistics and not ASC in academic writing and linguistics. Nonetheless, there are at least four plausible explanations for this result. First, participants who performed better in writing the method and results section of their scientific paper may have received more positive peer feedback on statistics, which resulted in greater gains in their ASC in statistics. Second, students may perceive tasks in statistics but not in academic writing as prevention tasks which may lead to the current results (Fedor et al. 2001; Van Dijk and Kluger 2011). Third, students self-rating on ASC in statistics may differ from those in academic writing and language regarding misjudgments. Students may judge their ASC in academic writing or language more accurate as compared to statistics, leading to less biased ratings of their own ASC in academic writing or language (e.g., Eccles and Wigfield 2002; Marsh et al. 2017). Fourth, the results may be due to ceiling effects, as the ASC in statistics was high at the beginning of the intervention already. The results may be different for students with low to medium ASC in a domain. So future studies could try to extent our findings in populations with lower ASC. The results lead to the question of comparisons of different aspects of ASC within domains, which seems to be promising to be addressed in future research.

\section{Generalizability of the Findings}

Overall, the finding of positive effects of peer feedback on ASC is robust, as we found it with different students, courses, contents, and instructors. We conducted a field experiment, which allowed for direct tests of causal hypotheses like laboratory experiments do. At the same time, field experiments have the high ecological validity of field studies. Thus, they combine the strengths of the other two approaches (Roe and Just 2009). However, the generalizability of the results is limited by some aspects of our study. First, our sample exclusively included psychology students and assessed only ASC regarding academic writing, language, and statistics. It is unknown to which extent the findings generalize to other academic domains or to other self-beliefs about academic competences (e.g., academic self-efficacy). To enhance the current understanding on the relationship between ASC and peer feedback our findings need to be replicated for other ASC domains, with other control groups and larger samples. Second, even though the sample demonstrated a high initial level of ASC in academic writing, the intervention was still effective in enhancing students' ASC. This raises the question, whether it is even desirable to enhance the students' ASC with an intervention from a teacher perspective as students may overestimate their abilities in a domain. Previous research suggests, that increasing high ASC is beneficial, even when students overestimate their own performance (Trautwein and Möller 2016) —at least to a certain degree, because students who overestimate their abilities in a specific academic domain might set themselves too high academic goals (e.g., always getting the best grades) and, therefore, possibly do not achieve these goals. These students then experience frustration and failure. Third, due to the lack of a follow-up test in our studies, nothing can be said about the stability of the positive effects over time. As demonstrated in a meta-analysis by 
O'Mara et al. (2006), there are moderately positive correlations between post-test and follow-up (3 weeks to 14 months). Fourth, we did not assess the students' performance after the peer feedback intervention (e.g., the following semester). Theoretically, the increase in ASC also increases future performance in academic writing tasks (Marsh 1990). Future studies can investigate this by adding two performance assessments, one before, and one after the intervention to the research design of the current study. This would give further insights into the complexity of effects of peer feedback on ASC and potential mediators and moderators.

\section{Theoretical and Practical Implications}

The study results have implications for future research and practice. As the intervention included both, giving feedback and receiving feedback, future studies need to investigate the specific cognitive processes underlying the positive causal effects of peer feedback on ASC and the relevance of feedback valence on these cognitive processes. There exists some evidence that providing peer feedback is more effective to enhance performance as compared to receiving feedback (Lundstrom and Baker 2009). However, this result cannot be transferred one to one to ASC. Underlying cognitive processes include, for example, the integration of evaluative information provided by others leading to a better self-understanding (Festinger 1954; Möller and Marsh 2013) or motivational components like accurate self-evaluation (Tesser 1988). One option for future research is to use learning diaries to elicit students' thoughts about their own academic competencies.

As we conducted one of the first studies on the effect of peer feedback on ASC in higher education, further research is needed to better understand the relationship between valence as well as content of peer feedback and the increase in academic self-beliefs such as ASC. There may be differences of the effect of feedback on ASC due to how students perceive peer feedback (Bong and Skaalvik 2003), due to the type of peer feedback, such as task, process, self-regulation, and self-feedback (Hattie and Timperley 2007), and due to the valence of the peer feedback. Based on the current findings, it seems promising to investigate the effects of peer feedback on ASC including feedback-related moderators, such as giving vs. receiving peer feedback in combination with positive vs. negative peer feedback. The results further provide scientific rationale for the implementation of peer feedback in higher education, as it is effective to enhance both, learning and motivational outcomes. This is of interest as the development of competencies such as the ability of valid selfappraisal is a relevant goal in higher education (van Dinther et al. 2011).

The present study gives an example of how online peer feedback can be employed in a practical setting. Online learning and blended learning environments become more popular due to an increase in distance education and MOOCS. Besides the benefits of open education such as open access education, there are also concerns about the teaching quality (Yuan and Powell 2013). Commonly students learn more self-directed and do not interact in online learning environments as actively as compared to face-to-face learning. However, attending a class actively is a key factor in student success and associated with higher learning gains (Schneider and Preckel 2017). Structured online peer feedback can serve an effective tool to promote interaction across students online and thus supporting their learning effectively. Some providers of MOOCs already successfully integrate peer assessments as a form of open assessment and evaluation of learning results in their courses (Yuan and Powell 2013). Due to the high practicability of online peer feedback and its more frequent application, it seems even more important to better understand its underlying principles. 
In sum, peer feedback has proven to enhance students' ASC in the domain of academic writing. As a method that actively engages students in their own process of learning and changing perspectives from an examinee to an examiner, peer feedback has the capacity to improve students' learning and academic self-beliefs. It is therefore a particularly promising teaching strategy to enhance intrapersonal competencies in higher education. Compared to other variables associated with academic outcomes in higher education, the effect of peer feedback on ASC with $d=0.721$ is comparable to the effect of social interaction on academic achievement in higher education, ranked as the 5th most important instruction variable (Schneider and Preckel 2017). The potential of peer feedback can be exhausted by following best practice strategies when implementing peer feedback in educational settings. The present study adds to the growing evidence that web-based peer feedback is a time- and cost-effective way to enhance not only achievement but also intrapersonal competencies such as academic self-beliefs in higher education.

Acknowledgements Open Access funding provided by Projekt DEAL.

Open Access This article is licensed under a Creative Commons Attribution 4.0 International License, which permits use, sharing, adaptation, distribution and reproduction in any medium or format, as long as you give appropriate credit to the original author(s) and the source, provide a link to the Creative Commons licence, and indicate if changes were made. The images or other third party material in this article are included in the article's Creative Commons licence, unless indicated otherwise in a credit line to the material. If material is not included in the article's Creative Commons licence and your intended use is not permitted by statutory regulation or exceeds the permitted use, you will need to obtain permission directly from the copyright holder. To view a copy of this licence, visit http://creativecommons.org/licenses/by/4.0/.

\section{References}

American Psychological Association. (2002). Ethical principles of psychologists and code of conduct. American Psychologist, 57(12), 1060-1073.

Arens, A. K., Bodkin-Andrews, G., Craven, R. G., \& Yeung, A. S. (2014). Self-concept of Indigenous and non-Indigenous Australian students: Competence and affect components and relations to achievement. Learning and Individual Differences, 32, 93-103.

Baadte, C., \& Schnotz, W. (2014). Feedback effects on performance, motivation and mood: Are they moderated by the learner's self-concept? Scandinavian Journal of Educational Research, 58(5), 570-591. https://doi.org/10.1080/00313831.2013.781059.

Baker, K. M. (2016). Peer review as a strategy for improving students' writing process. Active Learning in Higher Education, 17(3), 1-14. https://doi.org/10.1177/1469787416654794.

Bandura, A. (1986). Social foundations of thought and action: A social cognitive theory. Englewood Cliffs, NJ: Prentice-Hall.

Bargh, J. A., \& Schul, Y. (1980). On the cognitive benefits of teaching. Journal of Educational Psychology, 72(5), 593-604. https://doi.org/10.1037/0022-0663.72.5.593.

Black, P., \& William, D. (1998). Assessment and classroom learning. Assessment in Education, 5, 7-74. https://doi.org/10.1080/0969595980050102.

Bloom, A. J., \& Hautaluoma, J. E. (1987). Effects of message valence, communicator credibility, and source anonymity on reactions to peer feedback. The Journal of Social Psychology, 127(4), 329-338.

Bong, M., \& Skaalvik, E. M. (2003). Academic self-concept and self-efficacy: How different are they really? Educational Psychological Review, 15(1), 1-40. https://doi.org/10.1023/A:1021302408382.

Bouchey, H. A., \& Harter, S. (2005). Reflected appraisals, academic self-perceptions, and math/science performance during early adolescence. Journal of Educational Psychology, 97(4), 673-686. https://doi. org/10.1037/0022-0663.97.4.673.

Brown, S. (2010). Afterword. Assessment and Evaluation in Higher Education, 35, 347-349. https://doi. org/10.1080/02602931003690835. 
Brunner, M., Keller, U., Dierendonck, C., Reichert, M., Ugen, S., Fischbach, A., et al. (2010). The structure of academic self-concepts revisited: The nested Marsh/Shavelson model. Journal of Educational Psychology, 102(4), 964-981. https://doi.org/10.1037/a0019644.

Butler, D. L., \& Winne, P. H. (1995). Feedback and self-regulated learning: a theoretical synthesis. Review of Educational Research, 65(3), 245-281. https://doi.org/10.2307/1170684.

Byrne, B. M. (1984). The general/academic self-concept nomological network: A review of construct validation research. Review of Educational Research, 54(3), 427-456. https://doi.org/10.3102/0034654305 4003427.

Byrne, B. M., \& Gavin, D. A. (1996). The Shavelson model revisited: Testing for the structure of academic self-concept across pre-, early, and late adolescents. Educational Psychology, 88(2), 215-228.

Cartney, P. (2010). Exploring the use of peer assessment as a vehicle for closing the gap between feedback given and feedback used. Assessment \& Evaluation in Higher Education, 35, 551-564. https://doi. org/10.1080/02602931003632381.

Chen, S. K., Yeh, Y. C., Hwang, F. M., \& Lin, S. S. (2013). The relationship between academic self-concept and achievement: A multicohort-multioccasion study. Learning and Individual Differences, 23, 172-178. https://doi.org/10.1016/j.lindif.2012.07.021.

Cho, Y. H., \& Cho, K. (2011). Peer reviewers learn from giving comments. Instructional Science, 39(5), 629-643. https://doi.org/10.1007/s11251-010-9146-1.

Chodkiewicz, A. R., \& Boyle, C. (2014). Exploring the contribution of attribution retraining to student perceptions and the learning process. Educational Psychology in Practice, 30(1), 78. https://doi. org/10.1080/02667363.2014.880048.

Costello, J., \& Crane, D. (2013). Technologies for learner-centered feedback. Open Praxis, 5(3), 217-225.

Craven, R. G., Marsh, H. W., \& Debus, R. L. (1991). Effects of internally focused feedback and attributional feedback on enhancement of academic self-concept. Journal of Educational Psychology, 83(1), 17-27. https://doi.org/10.1037/0022-0663.83.1.17.

Dempsey, M. S., PytlikZillig, L. M., \& Bruning, R. H. (2009). Helping preservice teachers learn to assess writing: Practice and feedback in a Web-based environment. Assessing Writing, 14(1), 38-61. https://doi.org/10.1016/j.asw.2008.12.003.

Eccles, J. S., \& Wigfield, A. (2002). Motivational beliefs, values, and goals. Annual Review of Psychology, 53(1), 109-132. https://doi.org/10.1146/annurev.psych.53.100901.135153.

Evans, C. (2013). Making sense of assessment feedback in higher education. Review of Educational Research, 83(1), 70-120. https://doi.org/10.3102/0034654312474350.

Falchikov, N. (2001). Learning together: Peer tutoring in higher education. London: Psychology Press.

Falchikov, N., \& Goldfinsh, J. (2000). Student peer assessment in higher education: A meta-analysis comparing peer and teacher marks. Review of Educational Research, 70(3), 287-322. https://doi. org/10.3102/00346543070003287.

Fedor, D. B., Davis, W. D., Maslyn, J. M., \& Mathieson, K. (2001). Performance improvement efforts in response to negativefeedback: The roles of source power and recipientself-esteem. Journal of Management, 27, 79-97.

Festinger, L. (1954). A theory of social comparison processes. Human Relations, 7(117), 140. https:// doi.org/10.1177/001872675400700202.

Gielen, S., Dochy, F., Onghena, P., Struyven, K., \& Smeets, S. (2011). Goals of peer assessment and their associated quality concepts. Studies in Higher Education. https://doi.org/10.1080/0307507100 3759037.

Gogol, K., Brunner, M., Martin, R., Preckel, F., \& Goetz, T. (2017). Affect and motivation within and between school subjects: Development and validation of an integrative structural model of academic self-concept, interest, and anxiety. Contemporary Educational Psychology, 49, 46-65.

Guay, F., Larose, S., \& Boivin, M. (2004). Academic self-concept and educational attainment level: A tenyear longitudinal study. Self and Identity, 3(1), 53-68. https://doi.org/10.1080/13576500342000040.

Hattie, J. A. (2015). The applicability of visible learning to higher education. Scholarship of teaching and Learning in Psychology, 1(1), 79-91. https://doi.org/10.1037/st10000021.

Hattie, J. A., \& Timperley, H. (2007). The power of feedback. Review of Educational Research, 77(1), 81-112. https://doi.org/10.3102/003465430298487.

Hayes, A. F. (2013). Introduction to mediation, moderation, and conditional process analysis. New York: Guilford Press.

HEFCE. (2010). Effective practice in a digital age: A guide to technology-enhanced assessment and feedback. Retrieved from https://www.webarchive.org.uk/wayback/archive/20140614115719/http:// www.jisc.ac.uk/media/documents/programmes/elearning/digiassass_eada.pdf 
Jansen, M., Schroeders, U., Lüdtke, O., \& Marsh, H. W. (2015). Contrast and assimilation effects of dimensional comparisons in five subjects: An extension of the I/E model. Journal of Educational Psychology, 107(4), 1086-1101. https://doi.org/10.1037/edu0000021.

Kim, M. (2009). The impact of an elaborated assessee's role in peer assessment. Assessment \& Evaluation in Higher Education, 34, 105-114. https://doi.org/10.1080/02602930801955960.

Kluger, A. N., \& DeNisi, A. (1996). The effects of feedback interventions on performance: A historical review, a meta-analysis, and a preliminary feedback intervention theory. Psychological Bulletin, 119(2), 154-284. https://doi.org/10.1037/0033-2909.119.2.254.

Köller, O., Trautwein, U., Lüdtke, O., \& Baumert, J. (2006). Zum Zusammenspiel von schulischer Leistung, Selbstkonzept und Interesse in der gymnasialen Oberstufe. Zeitschrift für pädagogische Psychologie, 20(1/2), 27-39. https://doi.org/10.1024/1010-0652.20.12.27.

Lechermeier, J., \& Fassnacht, M. (2018). How do performance feedback characteristics influence recipients' reactions? A state-of-the-art review on feedback source, timing, and valence effects. Management Review Quarterly, 68(2), 145-193. https://doi.org/10.1007/s11301-018-0136-8.

Liu, N.-F., \& Carless, D. (2006). Peer feedback: The learning element of peer assessment. Teaching in Higher Education, 11(3), 279-290. https://doi.org/10.1080/13562510600680582.

Lizzio, A., \& Wilson, K. (2008). Feedback on assessment: Students' perceptions of quality and effectiveness. Assessment \& Evaluation in Higher Education, 33, 263-275. https://doi.org/10.1080/02602 930701292548.

Lundstrom, K., \& Baker, W. (2009). To give is better than to receive: The benefits of peer review to the reviewer's own writing. Journal of Second Landuage Writing, 18(1), 30-43.

Marcoulides, G. A., \& Simkin, M. G. (1995). The consistency of peer review in student writing projects. Journal of Business Education, 15(2), 118-141. https://doi.org/10.1080/08832323.1995.10117753.

Maringe, F. (2010). Leading learning: Enhancing the learning experience of university students through anxiety auditing. Education, Knowledge, and Economy, 4, 15-31. https://doi.org/10.1080/1749689100 3696470 .

Marsh, H. W. (1986). Verbal and math self-concepts: An internal/external frame of reference model. American Educational Research Journal, 23, 129-149. https://doi.org/10.2307/1163048.

Marsh, H. W. (1990). The causal ordering of academic self-concept and academic achievement: A multiwave, longitudinal panel analysis. Journal of Educational Psychology, 82(4), 646-656. https://doi. org/10.1037/0022-0663.82.4.646.

Marsh, H. W., Abduljabbar, A. S., Parker, P. D., Morin, A. J., Abdelfattah, F., Nagengast, B., et al. (2015). The internal/external frame of reference model of self-concept and achievement relations: Age-cohort and cross-cultural differences. American Educational Research Journal, 52(1), 168-202. https://doi. org/10.3102/0002831214549453.

Marsh, H. W., \& Hau, K.-T. (2003). Big-Fish-Little-Pond effect on academic self-concept: A cross-cultural (26-country) test of the negative effects of academically selective schools. American Psychologist, 58(5), 364-376. https://doi.org/10.1037/0003-066X.58.5.364.

Marsh, H. W., Martin, A. J., Yeung, A. S., \& Craven, R. G. (2017). Competence self-perceptions. In A. J. Elliot, C. Dweck, \& D. S. Yaeger (Eds.), Handbook of competence and motivation. Theory and application (pp. 85-115). New York: The Guildford Pressq.

Marsh, H. W., \& O’Neill, R. (1984). Self description questionnaire III: The construct validity of multidimensional self-concept ratings by late adolescents. Journal of Educational Measurement, 21(3), 153174. https://doi.org/10.1111/j.1745-3984.1984.tb00227.x.

Marsh, H. W., \& Shavelson, R. J. (2010). Self-concept: Its multifaceted, hierarchical structure. Educational Psychologist, 20(3), 107-123. https://doi.org/10.1207/s15326985ep2003_1.

Marsh, H. W., Trautwein, U., Lüdtke, O., Köller, O., \& Baumert, J. (2005). Academic self-concept, interest, grades, and standardized test scores: Reciprocal effects models of causal ordering. Child Development, 76(2), 397-416. https://doi.org/10.1111/j.1467-8624.2005.00853.x.

Möller, J., \& Marsh, H. W. (2013). Dimensional comparison theory. Psychological Review, 120(3), 544560. https://doi.org/10.1037/a0032459.

Möller, J., Pohlmann, B., Köller, O., \& Marsh, H. W. (2009). A meta-analytic path analysis of the internal/external frame of reference model of academic achievement and academic self-concept. Review of Educational Research, 79(3), 1129-1167. https://doi.org/10.3102/003465-4309337522.

National Academies of Sciences, Engineering, and Medicine (2017) Supporting students' college success: The role of assessment of intrapersonal and interpersonal competencies. Retrieved from Washington DC

Nelson, M. M., \& Schunn, C. D. (2009). The nature of feedback: How different types of peer feedback affect writing performance. Instructional Science, 37, 375-401. https://doi.org/10.1007/s11251-008-9053-x. 
Nicol, D. (2010). From monologue to dialogue: Improving written feedback processes in mass higher education. Assessment \& Evaluation in Higher Education, 35, 501-517. https://doi.org/10.1080/02602 931003786559.

Nicol, D., \& MacFarlane-Dick, D. (2005). Formative assessment and self-regulated learning: A model and seven principles of good feedback practice. Studies in Higher Education, 31(2), 199-218. https://doi. org/10.1080/03075070600572090.

Nilson, L. B. (2003). Improving student peer feedback. College Teaching, 51(1), 34-38. https://doi. org/10.1080/87567550309596408.

Núnez, J. C., González-Pienda, J. A., González-Pumariega, S., Roces, C., Alvarez, L., González, P.,..., Rodríguez, S. (2005). Subgroups of attributional profiles in students with learning difficulties and their relation to self-concept and academic goals. Learning Disabilities Research \& Practice, 20(2), 86-97. https://doi.org/10.1111/j.1540-5826.2005.00124.x.

O’Mara, A. J., Marsh, H. W., Craven, R. G., \& Debus, R. L. (2006). Do self-concept interventions make a difference? A synergistic blend of construct validation and meta-analysis. Educational Psychologist, 41(3), 181-206. https://doi.org/10.1207/s15326985ep4103_4.

Piech, C., Huang, J., Chen, Z., Do, C., Ng, A., \& Koller, D. (2013). Tuned models of peer assessment in MOOCs. Retrieved from https://web.stanford.edu/ cpiech/bio/papers/tuningPeerGrading.pdf

Pinquart, M., Juang, L. P., \& Silbereisen, R. K. (2003). Self-efficacy and successful school-to-work transition: A longitudinal study. Journal of Vocational Behavior, 63(3), 329-346. https://doi.org/10.1016/ S0001-8791(02)00031-3.

Pinxten, M., Marsh, H. W., De Fraine, B., Van Den Noortgate, W., \& Van Damme, J. (2014). Enjoying mathematics or feeling competent in mathematics? Reciprocal effects on mathematics achievement and perceived math effort expenditure. British Journal of Educational Psychology, 84(1), 152-174. https://doi.org/10.1111/bjep.12028.

Pond, K., Ul-Haq, R., \& Wade, W. (1995). Peer review: A precursor to peer assessment. Innovations in Education and Training International, 32(4), 314-323.

Richardson, M., Abraham, C., \& Bond, R. (2012). Psychological correlates of university students' academic performance: A systematic review and meta-analysis. Psychological Bulletin, 138(2), 353-387. https:// doi.org/10.1037/a0026838.

Robbins, S. B., Lauver, K., Le, H., Davis, D., Langley, R., \& Carlstrom, A. (2004). Do psychosocial and study skill factors predict college outcomes? A meta-analysis. Psychological Bulletin, 130(2), 261288. https://doi.org/10.1037/0033-2909.130.2.261.

Roe, B. E., \& Just, D. R. (2009). Internal and external validity in economics research: Tradeoffs between experiments, field experiments, natural experiments, and field data. American Journal of Agricultural Economics, 91(5), 1266-1271. https://doi.org/10.1111/j.1467-8276.2009.01295.x.

Rosenberg, M. (1979). Conceiving the self. New York: Basic Books.

Rust, C. (2002). The impact of assessment on student learning: How can the research literature practically help to inform the development of departmental assessment strategies and learner-centred assessment practices? Active Learning in Higher Education, 3, 145-158. https://doi.org/10.1177/1469787402 003002004.

Schiefele, U., Streblow, L., \& Brinkmann, J. (2007). Aussteigen oder durchhalten. Zeitschrift für Entwicklungspsychologie und Pädagogische Psychologie, 39(3), 127-140. https://doi. org/10.1026/0049-8637.39.3.127.

Schneider, M., \& Preckel, F. (2017). Variables associated with achievement in higher education: A systematic review of meta-analyses. Psychological Bulletin, Advance Online Publication.. https://doi. org/10.1037/bul0000098.

Skaalvik, E. M. (1997). Issues in research on self-concept (Vol. 10). New York: JAI Press.

Sluijsmans, D. M. A., Brand-Gruwel, S., \& van Merriënboer, J. J. G. (2002). Peer assessment training in teacher education: Effects on performance and perceptions. Assessment \& Evaluation in Higher Education, 27(5), 443-454. https://doi.org/10.1080/0260293022000009311.

Suen, H. K. (2014). Peer assessment for massive open online courses (MOOCs). The International Review of Research in Open and Distributed Learning. https://doi.org/10.19173/irrodl.v15i3.1680.

Taras, M. (2002). Using assessment for learning and learning from assessment. Assessment \& Evaluation in Higher Education, 27(6), 501-510. https://doi.org/10.1080/0260293022000020273.

Tesser, A. (1988). Toward a self-evaluation maintenance model of social behavior. In L. Berkowitz (Ed.), Advances in experimental social psychology (Vol. 21, pp. 181-227). New York: Academic Press.

Topping, K. J. (1998). Peer assessment between students in colleges and universities. Review of Educational Research, 68(3), 249-276. https://doi.org/10.3102/00346543068003249.

Topping, K. J. (2005). Trends in peer learning. Educational Psychology, 25(6), 631-645. https://doi. org/10.1080/01443410500345172. 
Topping, K. J., Smith, E. F., Swanson, I., \& Elliot, A. (2000). Formative peer assessment of academic writing between postgraduate students. Assessment \& Evaluation in Higher Education, 25(2), 149-169. https://doi.org/10.1080/713611428.

Trautwein, U., \& Möller, J. (2016). Self-concept: Determinants and consequences of academic self-concept in school contexts. In A. A. Lipnevich, F. Preckel, \& R. D. Roberts (Eds.), Psychosocial skills and school systems in the 21st century: Theory, research, and practice (pp. 187-214). Berlin: Springer.

Tseng, S.-C., \& Tsai, C.-C. (2007). On-line peer assessment and the role of the peer feedback: A study of high school computer course. Computers \& Education, 49(4), 1161-1174. https://doi.org/10.1016/j. compedu.2006.01.007.

Valentine, J. C., DuBois, D. L., \& Cooper, H. (2004). The relation between self-beliefs and academic achievement: A meta-analytic review. Educational Psychologist, 39(2), 111-133. https://doi. org/10.1207/s15326985ep3902_3.

Van Dijk, D., \& Kluger, A. N. (2011). Task type as a moderator of positive/negativefeedback effects on motivation and performance: A regulatory focus perspective. Journal of Organizational Behavior, 32, 1084-1105.

van Dinther, M., Dochy, F., \& Segers, M. (2011). Factors affecting students' self-efficacy in higher education. Educational Research Review, 6(2), 95-108. https://doi.org/10.1016/j.edurev.2010.10.003.

Vancouver, J. B., \& Tischner, E. C. (2004). The effect of feedback sign on task performance depends on self-concept discrepancies. Journal of Applied Psychology, 89(6), 1092-1098.

Venables, A., \& Summit, R. (2003). Enhancing scientific essay writing using peer assessment. Innovations in Education and Teaching International, 40(3), 281-290. https://doi.org/10.1080/147032903200010 3816.

Yuan, L., \& Powell, S. (2013). MOOCs and open education: Implications for higher education. Retrieved from https://publications.cetis.ac.uk/2013/667

Publisher's Note Springer Nature remains neutral with regard to jurisdictional claims in published maps and institutional affiliations. 